\title{
ASSESSMENT OF HEALTH INEQUALITIES AMONG OLDER PEOPLE USING THE EPICES SCORE: A COMPOSITE INDEX OF SOCIAL DEPRIVATION
}

\author{
B. BONGUE ${ }^{1,3}$, A. COLVEZ ${ }^{1,4}$, E. AMSALLEM ${ }^{1}$, L. GERBAUD ${ }^{1,2}$, C. SASS 1 \\ 1. Centre technique d'appui et de formation des centres d'examens de santé (Cetaf), France; 2. CHU de Clermont-Ferrand ; Laboratoire EA 4681 PEPRADE, Université d'Auvergne, \\ Clermont-Ferrand, France; 3. Laboratoire EA 4607 SNA-EPIS, Université Jean Monnet Saint-Étienne, France; 4. Géronto-CLEF, Montpellier, France \\ Corresponding author: Bienvenu Bongue, PhD, 67-69 Avenue de Rochetaillée, 42100 Saint-Étienne, France, Tel: + 33 -4-77 81 63 73, Fax: +33 -4-77 811718 , \\ E-mail: bienvenu.bongue@cetaf.fr
}

\begin{abstract}
Background: Most of the indicators commonly used to assess social deprivation are poorly suited to study health inequalities in older people. The EPICES (Evaluation of Deprivation and Inequalities in Health Examination Centres) score is a new composite index commonly used to measure individual deprivation. Objective: To assess the relationships between health indicators and the EPICES score in older people. Design, Setting, and participants: We performed a cross-sectional study using the data from the 2008 ESPS Survey (Health, HealthCare and Insurance Survey). Of the 4235 survey respondents aged 60 and over in 2008, 2754 completed the 11 items of the EPICES score and were included in the study. Main outcomes and measures: Deprivation was measured using the EPICES score. Health indicators were: Disability, physical performance, cognitive decline, self-perceived health status, and health-care use and participation in prevention programs (missing teeth not replaced, healthcare renunciation, no hemoccult test [60-75 years] and no mammography [60-75 years]). Results: Of the 4235 survey respondents aged 60 and over in 2008, 2754 completed the 11 items of the EPICES score and were included in the study. The mean age was 70.5 8.2 years. 52.8\% were women. $25.8 \%$ were living in poor households. According to the EPICES score, $35.1 \%$ were deprived. The EPICES score is linked to all the health indicators assessed in this study: Physical disability, cognitive decline; lifestyle and health care accessibility. These relationships increase steadily with the level of social deprivation. For example, the risk of having difficulties in walking $500 \mathrm{~m}$ without help or an assistive device is multiplied by 13 (RR=13.5 [7.9-20.8]) in the elderly of quintile 5 (maximum precariousness). Limitations: The observational nature limits inferences about causality. Conclusion: The EPICES score is linked to health indicators. It could be a useful instrument to assess health inequalities in older people living in the community.
\end{abstract}

Key words: Health inequalities, deprivation, older people.

\section{Introduction}

With the ageing of the population, analysis of health inequalities among older people has become a priority in public health (1). Although research on this topic is increasing, it does remain sparse. Two major explanations could support this paucity of research of health inequalities in older people: past assumptions of homogeneity of older people and difficulties in measuring social deprivation or socio-economic position (SEP) in this population (2). Therefore the relationship between health inequalities and social deprivation remains confused in older people. Some studies have suggested that there is only a weak relationship between social deprivation and ill health in older adults (3) or that there is a lower mortality differential between older people living in affluent and deprived areas(4).

Over the past 2 decades there has been a stereotypical view of older people as a homogeneous social group - an acceptance of the view that old age is a time of universal and inevitable biological decline resulting in universal ill health and therefore SEP not being an important variable of differentiation amongst older people (5). However, as in the working age population, recent studies suggest health inequalities in older people even in later life (6-8)
The second explanation concerns the measurement of SEP in older people. Measuring SEP or social deprivation in older adults is an important challenge. O'Reilly highlights the difficulties in using established SEP measures in older people and concludes that many of the commonly used indicators to measure social deprivation are inherently biased against older people (9). Hyde and Jones showed the importance of using a composite indicator (10).

In the French preventive Health Examination Centres (HEC) in addition to the administrative legal definition of social deprivation (11), social and material deprivation is measured using the EPICES score (EPICES; Evaluation of Deprivation and Inequalities in Health Examination Centres). The EPICES score was developed in 2002 and was based on an initial questionnaire of 42 items selected by a panel of French experts from the National Health Insurance relative to dimensions of deprivation as defined by Wrezinski and Townsend (12, 13). A factorial correspondence analysis identified 11 salient items of which calculation of the EPICES score. The score is computed by adding each question coefficient to intercept whenever the answer is «yes». This tool takes into account multiple dimensions of socioeconomic conditions, including psychological aspects and social support $(14,15)$. In a previous 


\section{THE JOURNAL OF FRAILTY \& AGING}

study, our team has shown the relevance of categorization of the EPICES score (15).

The EPICES score was validated in people aged 18 to 59 years old (15). Although the usefulness of this tool was previously shown in various populations (16-20), it has been scarcely used in older people.

The aim of this study was to assess the relationships between health indicators and the EPICES score in older people using data from the French ESPS survey (Enquête Santé Protection Sociale) conducted in 2008.

\section{Materials and Methods}

\section{Population}

Our study was performed using data from the 2008 ESPS Survey (Health, HealthCare and Insurance Survey (ESPS) (21). In France, the ESPS survey collects detailed selfreported information on morbidity every two years. This survey is a representative sample of National Health Insurance Beneficiaries. Of the 4235 survey respondents aged 60 and over in 2008, 2754 completed the 11 items of the EPICES score and were included in the study. The completion ratio was $65 \%$.

The study was conducted in accordance with the ethical standards set forth in the Helsinki Declaration (1983). A written informed consent for participation was obtained for participants.

\section{Outcomes}

- Deprivation was assessed using the EPICES score. This score is calculated according to an algorithm based on the response to 11 questions (Appendix 1), and varies from 0 (the least deprived) to 100 (the most deprived) (22). Although the EPICES score has a continuous distribution (as an increase in the score shows an increase in social deprivation and its consequences), a deprivation state is usually defined as a score of $\geq 30.17$. However the EPICES score can also be used as a continuous variable divided into 5 equally sized groups.

- The occupation was subdivided into 7 classes: farmers, artisans/traders, executives, middle management, employees, workers and others grouping/including people with no professional activity. Retirees are classified according to their former category.

- The poverty line is the minimum level of income deemed adequate in a particular country. In France, the poverty line was 949 euros in 2008. Households with income per consumption unit below the poverty line were defined as «poor households».

\section{Health indicators}

Health indicators were assessed using a self-report questionnaire. Participants with chronic disease were those reporting at least one chronic disease during the interview. The BMI (body mass index) was used to assess obesity (BMI $\geq 30$ $\mathrm{kg} / \mathrm{m}^{2}$ ). Disability was assessed by limitation of usual activities for at least six months due to a health problem. Difficulties in walking 500m without help or an assistive device, difficulties in going up or down stairs without help or an assistive device, and difficulties in washing themselves were used to assess physical performance. The inability to remember what time of the day it was, was used to assess cognitive decline. Health-care use and participation in prevention programs were assessed using data from: number of missing teeth not replaced, healthcare renunciation, participation in colorectal cancer screening (hemoccult test [60-75 years]), and participation in breast cancer screening (mammography [60-75 years]). The other predictors examined were age, sex, current tobacco use, self-perceived health status, missing teeth not replaced, and healthcare renunciation (23).

\section{Statistical analyses}

All analyses were performed using the SPSS v18 software for Windows (SPSS Inc., Chicago, IL). Descriptive analyses were used to describe the sample studied. The population was divided into quintiles according to the EPICES score. Quintile 1 involved subjects with the lowest scores (equivalent to no precariousness or social deprivation) and quintile 5, subjects with the highest score (maximum precariousness). Quintile 1 was the reference category. Bivariate and multivariate analyses were performed. Multiple logistic regression adjusted to sex and age was used to analyse the relationship between the quintiles of the EPICES score, health status and sociodemographic variables. Adjusted relative risks (RRs) and their $95 \%$ confidence intervals (CIs) were calculated.

\section{Results}

The study population included 2,754 subjects aged 60 and over who filled in all 11 questions of the EPICES score in the 2008 ESPS Survey. The mean EPICES score was $22.0 \pm 17.8$ $[0-90.5]$. The mean age of the study sample was $70.5 \pm 8.2$ years [min: 60; $\max 100$ ]. $52.8 \%$ of participants were women. $25.8 \%$ lived in poor households. According to the EPICES score, $35.1 \%$ of participants were deprived. $25.8 \%$ lived in poor households. $46.5 \%$ of participants reported at least one chronic disease. The characteristics of the study sample are presented in table 1 . The risk of belonging to the blue-collar social category or a poor household category increases with the «EPICES score» quintiles. Thus, an elderly person with an EPICES score greater than 48.52 (Quintile 5) is 3.4 times more likely to belong to the blue collar category and 6.4 times more likely to belong to a poor household (Table 2).

The increase of the EPICES score is linked to a worsening of all the health indicators assessed in our study: physical disability, cognitive decline, lifestyle and health care accessibility (Table 2). These relationships increase steadily with the level of social deprivation. The most significant relationships are observed for physical disability indicators in particular. For example, the risk of having difficulties in walking $500 \mathrm{~m}$ without the help of someone or an assistive 


\section{ASSESSMENT OF HEALTH INEQUALITIES AMONG OLDER PEOPLE USING THE EPICES SCORE}

device is multiplied by 13 ( $\mathrm{RR}=13.5$ [95\%CI 7.9-20.8]) in the older people of quintile 5 (maximum precariousness). After adjustments of the poverty status or the socio-professional category, trends did not change and all relationships remained statistically significant (data not shown).

Table 1

Characteristics of the study sample

\begin{tabular}{|c|c|c|}
\hline & $\mathbf{N}$ & $\%$ \\
\hline Sex (women) & 1455 & 52.8 \\
\hline \multicolumn{3}{|l|}{ Age classes (years) } \\
\hline $60-74$ & 1908 & 69.3 \\
\hline $75-84$ & 674 & 24.5 \\
\hline$\geq 85$ & 172 & 6.2 \\
\hline \multicolumn{3}{|l|}{ Occupations } \\
\hline Farmers & 250 & 9.1 \\
\hline Artisans/ Traders & 247 & 9.0 \\
\hline Executive & 388 & 14.1 \\
\hline Intermediate & 490 & 17.8 \\
\hline White-collar & 630 & 22.9 \\
\hline Blue-collar & 685 & 24.9 \\
\hline Others & 57 & 2.1 \\
\hline Poor households* & 608 & 25.8 \\
\hline EPICES score (mean \pm standard deviation, range) & \multicolumn{2}{|c|}{$22.0 \pm 17.8(0-90.5)$} \\
\hline Quintile $1[0-7.10]$ & 459 & 16.7 \\
\hline Quintile 2 [7.11-16.56] & 597 & 21.7 \\
\hline Quintile 3 [16.57-30.17] & 733 & 26.6 \\
\hline Quintile 4 [30.18-48.52] & 713 & 25.9 \\
\hline Quintile 5 [48.53-100] & 252 & 9.2 \\
\hline Smokers & 228 & 8.2 \\
\hline Obesity (BMI $\geq 30 \mathrm{~kg} / \mathrm{m}^{2}$ ) & 481 & 17.5 \\
\hline Chronic disease(s) & 1281 & 46.5 \\
\hline Poor health status $\dagger$ & 1321 & 48.0 \\
\hline Healthcare renunciation over the past 12 months\# & 329 & 11,9 \\
\hline At least 5 missing teeth not replaced & 804 & 29.2 \\
\hline Difficulties in washing themselves & 249 & 9.0 \\
\hline $\begin{array}{l}\text { Difficulties in walking } 500 \mathrm{~m} \text { without someone's } \\
\text { help or an assistive device }\end{array}$ & 494 & 17.9 \\
\hline No Hemoccult test [60-75 years] & 1058 & 54.1 \\
\hline No mammography [60-75 years] & 59 & 5.9 \\
\hline Cognitive decline $\S$ & 311 & 11.3 \\
\hline
\end{tabular}

* Poverty line was 949 euros in 2008 in France; $\uparrow$ Poor health status: a value of $\leq 7$ represented a poor health status in a visual analogue scale [0-10]; \# An indicator of equality in health care access; § Cognitive decline: Not remembering what time of the day it is

\section{Discussion}

The present study demonstrated that the deprivation state assessed by the EPICES score is significantly related to health indicators and standard indicators of social deprivation such as occupation and poverty. The EPICES score includes 11 items assessing various dimensions of deprivation in one multicomposite scale. This is especially true for the items focusing on social support, which is very important for the assessment of needs in frail older people. Price (24) suggests the need for a multi-component tool to measure social inequality or deprivation in older people. Our results suggest that the EPICES score would be a suitable screening tool for this population.

This study also demonstrated for the first time strong links between deprivation and physical disability in older people (difficulties in walking 500 meters without an assistive device, difficulties in going up or down stairs without help or assistance, and difficulties in washing themselves). These relationships are proportional ("score-dependent"), showing the suitability of using the quantitative version of the EPICES score in older people. Our results also showed that the EPICES score was related to several economic indicators (occupation, poverty), lifestyle (tobacco consumption, health-care use), dental status and obesity. These results are in accordance with our previous study (15) and suggest the usefulness of this tool in older people living in the community.

The ESPS is the sole representative sample of French National Health Insurance beneficiaries which covers 85\% of the French population. However, these findings should be interpreted with caution. We performed a cross-sectional study. Thus the relationships observed in this study cannot lead to the conclusion that there is a casual link between various variables. Another limitation could be a non-response bias. The completion ratio was $65 \%$. There was no difference between respondents and non-respondents in terms of sex and age. However there was a difference in income (poverty) between the groups. The non-respondents mostly came from poor households ( $33.9 \%$ vs. $25.8 \%$; $\mathrm{p}<0.001)$.

Few deprivation screening tools were described in the literature (the NZiDep)(25), the FWID (26) and the DIPCare-Q (27). These screening tools were scarcely used in older people and some of them were poorly adapted to the French setting. When performing an assessment of needs in retired people, income as well as social support (by a social worker or/and family support) should be taken into account. The best advantage of the «EPICES score» is that, while this index includes various items to assess social support, the tool is easy to use and not time-consuming (22). Furthermore, we have previously shown that the associations between the EPICES score and the health variables were stronger than those observed with the French administrative definition of precariousness (28). 
Table 2

Prevalence and RR [95\%CI] between socioeconomic status, health indicators and the «EPICES score»

Socioeconomic status and health indicators

Blue-collar (Occupations)

Poor households*

$\begin{array}{lccccc}\text { Prevalence }(\%) & 10.9 & 17.4 & 23.9 & 35.9 & 40.6 \\ \text { RR } & 1.0[\mathrm{ref}] & 1.9[1.5-2.3] & 2.5[2.1-2.8] & 3.2[2.9-3.4] & 3.4[3.1-3.6]\end{array}$

$\begin{array}{lccccc}\text { Prevalence }(\%) & 7.1 & 12.4 & 26.6 & 39.9 & 50.7 \\ \text { RR } & 1.0[\text { ref] } \dagger & 1.6[1.0-2.4] & 3.1[2.2-4.3] & 4.8[3.6-6.2] & 6.4[4.8-8.1]\end{array}$

Poor health status $\ddagger$

$\begin{array}{lccccc}\text { Prevalence }(\%) & 25.5 & 35.1 & 52.9 & 61.8 & 72.5 \\ \text { RR } & 1.0[\mathrm{ref}] & 1.3[1.1-1.6] & 1.8[1.6-2.1] & 2.2[1.9-2.4] & 2.7[2.4-3.0]\end{array}$

Chronic disease

At least 5 missing teeth not replaced

$\begin{array}{lccc}\text { Prevalence }(\%) & 40.7 & 43.1 & 53.0 \\ \text { RR } & 1.0[\mathrm{ref}] & 1.0[0.9-1.2] & 1.2[1.0-1.3\end{array}$

$\begin{array}{lll}\text { Prevalence }(\%) & 16.0 & 21.7\end{array}$

RR 1.0 [ref]

Limitation of usual activities for at least six months due to a health problem

$\begin{array}{lc}\text { Prevalence (\%) } & 17.4 \\ \text { RR } & 1.0 \text { [ref] }\end{array}$

Difficulties in walking 500m without someone's help or an assistive device

$\begin{array}{lcc}\text { Prevalence (\%) } & 2.2 & 6.1 \\ \text { RR } & 1.0[\mathrm{ref}] & 2.2[1.1-4.4]\end{array}$

Difficulties in going up or down stairs without someone's help or an assistive device

\begin{tabular}{|c|c|c|c|c|c|}
\hline Prevalence $(\%)$ & 4.9 & 7.9 & 25.7 & 32.1 & 50.2 \\
\hline RR & $1.0[\mathrm{ref}]$ & $1.3[0.8-2.2]$ & $3.6[2.4-5.2]$ & $4.5[3.0-6.3]$ & $8.7[6.2-11.3]$ \\
\hline Prevalence $(\%)$ & 2.2 & 4.0 & 8.6 & 15.4 & 22.6 \\
\hline RR & 1.0 [ref] & $1.6[0.7-3.2]$ & $2.4[1.2-4.5]$ & $4.3[2.3-7.8]$ & $7.0[3.7-12.3]$ \\
\hline \multicolumn{6}{|l|}{ is } \\
\hline Prevalence $(\%)$ & 4.2 & 6.2 & 11.1 & 16.1 & 25.1 \\
\hline RR & 1.0 [ref] & $1.4[0.8-2.4]$ & $2.2[1.4-3.5]$ & $3.2[2.0-4.9]$ & $5.3[3.4-7.9]$ \\
\hline Prevalence $(\%)$ & 12.8 & 15.8 & 18.5 & 21.4 & 23.9 \\
\hline RR & $1.0[\mathrm{ref}]$ & $1.2[0.9-1.7]$ & $1.5[1.2-2.0]$ & $1.8[1.3-2.3]$ & $2.0[1.4-2.6]$ \\
\hline Prevalence $(\%)$ & 5.4 & 7.4 & 10.3 & 9.0 & 13.7 \\
\hline RR & 1.0 [ref] & $1.6[1.0-2.6]$ & $2.5[1.6-3.8]$ & $2.4[1.5-3.6]$ & $3.6[2.2-5.5]$ \\
\hline \multicolumn{6}{|l|}{ months } \\
\hline Prevalence $(\%)$ & 5.5 & 8.7 & 9.3 & 15.7 & 32.4 \\
\hline RR & 1.0 [ref] & $1.6[1,0-2.6]$ & $2.0[1.3-3.0]$ & $3.4[2.3-4.8]$ & $6.5[4.6-8.7]$ \\
\hline Prevalence $(\%)$ & 52.8 & 54.0 & 58.4 & 61.4 & 63.8 \\
\hline RR & $1.0[\mathrm{ref}]$ & $1.0[0.9-1.1]$ & $1.1[1.0-1.2]$ & $1.2[1.0-1.3]$ & $1.2[1.0-1.4]$ \\
\hline Prevalence $(\%)$ & \multicolumn{2}{|r|}{1.5} & 7.4 & 11.0 & 12.4 \\
\hline RR & \multicolumn{2}{|r|}{1.0 [ref] } & $3.9[1.7-8.5]$ & $5.4[2.5-11.0]$ & $7.1[3.0-15.2]$ \\
\hline
\end{tabular}

Difficulties in washing themselves

$$
27.7
$$$$
1.5[1.2-1.9]
$$

$$
\begin{gathered}
34.7 \\
1.9[1.5-2.3]
\end{gathered}
$$

39.7

$$
1.9 \text { [1.6-2.3] }
$$

21.1

6,0 [3.3-10.3]

55.7

62.7

1.3 [1.1-1.4]

$1.4[1.2-1.6]$

50.4

2.2 [1.8-2.7]

2.9 [2.3-3.5]

59.8

2.4 [2.0-2.8] $3.2[2.6-3.7]$

38.9

28.2

8.0 [4.5-13.3]

13,5 [7.9-20.8]

\section{Prevalence (\%)}

4.9

$1.3[0.8-2.2]$

Difficulties in going up or down stairs withor$$
\text { Pre }
$$

Not remembering what time of the day it is


class: Executives; $¥$ Poor health status (a value of $\leq 7$ represented a poor health status in a visual analogue scale [0-10]); \# For the mammography screening analyses, two EPICES score classes (Q1 and Q2) were merged (sample size) 


\section{Conclusion}

The EPICES score is linked to health indicators and can identify social deprivation in older people. This screening tool can be a useful instrument to measure deprivation in older people living in the community. Due to the fact that the relationships observed in this study are score-dependent, the quantitative form may be more useful in older people. Thus, gradients in health inequalities can be investigated.

Competing interests: The authors declare that they have no competing interests.

Acknowledgements: The authors thank all the study participants, the investigators of IRDES (Institut de recherche et documentation en économie de la santé) and specially Mr Yann BOURGUEIL and Mr Thierry ROCHEREAU. We also thank Mr Norbert DEVILLE the director of the technical support and training centre for the French health examination centres (CETAF: Centre technique d'appui et de formation des centres d'examens de santé) for the administrative support. This work was supported by the CETAF.

\section{References}

1. Artazcoz L, Rueda S. Social inequalities in health among the elderly: a challenge for public health research. J Epidemiol Community Health 2007;61(6):466-7.

2. Galobardes B, Shaw M, Lawlor DA, Lynch JW, Davey Smith G. Indicators of socioeconomic position (part 1). J Epidemiol Community Health 2006;60(1):7-12.

3. Arber S, Ginn J. Gender and inequalities in health in later life. Soc Sci Med 1993;36(1):33-46.

4. Carstairs V, Morris R. Deprivation: explaining differences in mortality between Scotland and England and Wales. BMJ 1989;299:886-9.

5. Victor CR. Inequalities in health in later life. Age Ageing 1989;18(6):38791.

6. Lang IA, Llewellyn DJ, Langa KM, Wallace RB, Melzer D. Neighbourhood deprivation and incident mobility disability in older adults. Age Ageing 2008;37(4):403-10.

7. Lang IA, Llewellyn DJ, Langa KM, Wallace RB, Huppert FA, Melzer D. Neighborhood deprivation, individual socioeconomic status, and cognitive function in older people: analyses from the English Longitudinal Study of Ageing. J Am Geriatr Soc 2008;56(2):191-8.

8. Arber S, Cooper H. Gender differences in health in later life: the new paradox? Soc Sci Med 1999;48(1):61-76.

9. O'Reilly D. Standard indicators of deprivation: do they disadvantage older people? Age Ageing 2002;31(3):197-202.

10. Hyde M, Jones IR. The long shadow of work - does time since labour market exit affect the association between socioeconomic position and health in a post-working population. J Epidemiol Community Health 2007;61(6):533-9.
11. Sass C, Gueguen R, Moulin JJ, et al. [Comparison of the individual deprivation index of the French Health Examination Centres and the administrative definition of deprivation]. Sante Publique 2006;18:513-22.

12. Wrezinski J. Grande pauvreté et précarité économique et sociale : rapport présenté au nom du Conseil Economique et Social. Journal Officiel Avis et rapports du Conseil Economique et Social 1987;(6):1-104.

13. Townsend P. Deprivation. J Social Policy 1987;16:125-46.

14. Labbe E, Moulin JJ, Gueguen R, Sass C, Chatain C, Gerbaud L. Un indicateur de mesure de la précarité et de la «santé sociale»: le score EPICES. L'expérience des Centres d'examens de santé de l'Assurance maladie. La Revue de l'Institut de Recherches Economiques et Sociales (IRES) 2007;(53):3-50.

15. Sass C, Moulin JJ, Guéguen R, et al. Le score EPICES: un score individuel de précarité. Construction et évaluation du score dans une population de 197389 personnes. Bull Epidemiol Heb 2006;(14):93-6.

16. Convers M, Langeron A, Sass C, et al. [Is the socioeconomic deprivation EPICES score useful in obstetrics?]. Gynecol Obstet Fertil 2012;40(4):208-12.

17. Bihan $\mathrm{H}$, Laurent $\mathrm{S}$, Sass $\mathrm{C}$, et al. Association among individual deprivation, glycemic control and diabetic complication - The EPICES score. Diabetes Care 2005;28(11):2680-5.

18. Belin S. Utilisation du score EPICES pour évaluer la précarité des victimes de violences volontaires (étude transversale au CHU de SaintEtienne sur 275 victimes vues en consultation de médecine légale [Thèse de doctorat d'Etat en Médecine]. Université Jean Monnet, Faculté de Médecine Jacques Lisfranc, Saint Etienne. 2007

19. Lelong A, Jiroff L, Blanquet M, et al. Is idividual social deprivation associated with adverse perinatal outcomes? results of a French multicentre cross-sectional survey. J Prev Med Hyg 2015;56:E95-E101.

20. Bihan H, Ramentol M, Fysekidis M, et al. Screening for deprivation using the EPICES score: a tool for detecting patients at high risk of diabetic complications and poor quality of life. Diabetes Metab 2012;38(1):82-5.

21. Allonier C, Dourgnon P, Rochereau T. Enquête sur la santé et la protection sociale 2008. Paris: IRDES 256p. 2010

22. Moulin JJ, Dauphinot V, Dupré C, et al. Inégalités de santé et comportements: comparaison d'une population de 704128 personnes en situation de précarité à une population de 516607 personnes non précaires, France, 1995-2002. Bull Epidemiol Heb 2005;(43):213-5.

23. Desprès C. Signification du renoncement aux soins: Une analyse anthropologique. Sciences Sociales et Santé 2013;31(2):71-96.

24. Price D. Measuring the poverty of older people: A critical review. London: King's College London 220p. 2008

25. Salmond C, Crampton P, King P, Waldegrave C. NZiDep: a New Zealand index of socioeconomic deprivation for individuals. Soc Sci Med 2006;62(6):1474-85.

26. Eroglu S. Developing an index of deprivation which integrates objective and subjective dimensions : extending the work of Towsend, Mack and Lansley, and Halleröd. Soc Indicators Res 80p. 2007

27. Vaucher P, Bischoff T, Diserens EA, et al. Detecting and measuring deprivation in primary care: development, reliability and validity of a selfreported questionnaire: the DiPCare-Q. BMJ Open 2012;2(1):e000692.

28. Sass C, Guéguen R, Moulin JJ, et al. Comparaison du score individuel de précarité des Centres d'examens de santé, EPICES, à la définition socioadministrative de la précarité. Santé publique 2006;18(4):513-22. 


\section{THE JOURNAL OF FRAILTY \& AGING}

\section{Appendix 1}

EPICES score (Evaluation de la Précarité et des Inégalités de santé dans les Centres d'Examens de Santé - Evaluation of Deprivation and Inequalities in Health Examination Centres)

\begin{tabular}{|c|c|c|}
\hline \multirow[t]{2}{*}{ Questions } & \multicolumn{2}{|c|}{ Score } \\
\hline & Yes & No \\
\hline 1. Do you sometimes meet with a social worker (welfare worker, educator)? & 10.06 & 0 \\
\hline 2. Do you have complementary health insurance (mutual insurance)? & -11.83 & 0 \\
\hline 3. Do you live as a couple? & -8.28 & 0 \\
\hline 4. Are you a homeowner or will you be one in the near future? & -8.28 & 0 \\
\hline 5. Are there periods in the month when you have real financial difficulties in facing you needs (food, rent, electricity)? & 14.80 & 0 \\
\hline 6. Have you participated in any sports activities in the last 12 months? & -6.51 & 0 \\
\hline 7. Have you gone to any shows (cinema, theatre) in the last 12 months? & -7.10 & 0 \\
\hline 8. Have you gone on holiday during the past 12 months? & -7.10 & 0 \\
\hline 9. Have you seen any family members in the past six months (other than your parents or children)? & -9.47 & 0 \\
\hline 10. Did you have difficulties (financial, family or health), is there anyone around you who could take you in for a few days? & -9.47 & 0 \\
\hline $\begin{array}{l}\text { 11. Did you have difficulties (financial, family or health), is there anyone around you who could help you financially (material aid such as lending } \\
\text { you money)? }\end{array}$ & -7.10 & 0 \\
\hline Intercept & 75.14 & 0 \\
\hline
\end{tabular}

